Article

\title{
An inclination in Thermal Energy Using Nanoparticles with Casson Liquid Past an Expanding Porous Surface
}

\author{
Umar Nazir $^{1, *}$, Muhammad Sohail ${ }^{1, * \mathbb{D}}$, Muhammad Bilal Hafeez ${ }^{2} \mathbb{D}$, Marek Krawczuk $^{2} \mathbb{D}$, Sameh Askar $^{3} \mathbb{D}$ \\ and Sammar Wasif 1 \\ 1 Department of Applied Mathematics and Statistics, Institute of Space Technology, P.O. Box 2750, \\ Islamabad 44000, Pakistan; samar.wasif@gmail.com \\ 2 Institute of Mechanics and Machine Design, Faculty of Mechanical Engineering and Ship Technology, \\ Gdansk University of Technology, Narutowicza 11/12, 80-233 Gdańsk, Poland; \\ muhammad.bilal.hafeez@pg.edu.pl (M.B.H.); marek.krawczuk@pg.edu.pl (M.K.) \\ 3 Department of Statistics and Operations Research, College of Science, King Saud University, P.O. Box 2455, \\ Riyadh 11451, Saudi Arabia; saskar@ksu.edu.sa \\ * Correspondence: nazir_u2563@yahoo.com (U.N.); muhammad_sohail111@yahoo.com (M.S.)
}

Citation: Nazir, U.; Sohail, M.; Hafeez, M.B.; Krawczuk, M.; Askar, S.; Wasif, S. An inclination in Thermal Energy Using Nanoparticles with Casson Liquid Past an Expanding Porous Surface. Energies 2021, 14, 7328. https://doi.org/10.3390/ en14217328

Academic Editor: Jianchao Cai

Received: 18 October 2021

Accepted: 1 November 2021

Published: 4 November 2021

Publisher's Note: MDPI stays neutral with regard to jurisdictional claims in published maps and institutional affiliations.

Copyright: (c) 2021 by the authors. Licensee MDPI, Basel, Switzerland. This article is an open access article distributed under the terms and conditions of the Creative Commons Attribution (CC BY) license (https:// creativecommons.org/licenses/by/ $4.0 /)$.

\begin{abstract}
The physical aspects of inclined MHD nanofluid toward a stretching sheet embedded in a porous medium were visualized, which has numerous applications in industry. Two types of nanoparticles, namely copper and aluminum oxide, were used, with water (limiting case of Casson liquid) as the base fluid. Similarity transformations were used to convert the partial differential equations into a set of ordinary differential equations. Closed solutions were found to examine the velocity and temperature profiles. It was observed that an increment in the magnitude of the Hartmann number, solid volume fraction, and velocity slip parameter brought a reduction in the velocity profile, and the opposite behavior was shown for the permeability parameter in $\mathrm{Cu}$-water and $\mathrm{Al}_{2} \mathrm{O}_{3}$-water nanofluids. The temperature field, local skin friction, and local Nusselt number were further examined. Moreover, the study of $\mathrm{Cu}$ and $\mathrm{Al}_{2} \mathrm{O}_{3}$ is useful to boost the efficiency of thermal conductivity and thermal energy in particles. Reduction was captured in the velocity gradient and temperature gradient against changes in the thermal radiation number. The opposite trend was tabulated into motion with respect to the volume fraction number for both cases ( $\mathrm{Cu}$-water and $\mathrm{Al}_{2} \mathrm{O}_{3}$-water).
\end{abstract}

Keywords: porous heat surface; magnetohydrodynamic; thermal properties; thermal enhancement; surface force

\section{Introduction}

Magneto-hydrodynamics (MHD) is the examination of fluid mechanics associated with electrically conducting fluids alongside an electromagnetic field, which has huge industrial applications. MHDs have various applications, which are dependent on their extensive utilization in industry and are used at the mechanical level. For example, just a few specific applications are MHD power generators, nuclear reactor cooling, small MHD pumps, bearing, and limit layer impact, which are affected by the relationship to magnetic fields and the electrically conducting fluid. The hydrodynamic limit (boundary) layers are fundamentally influenced by the electrically conducting fluid and magnetic fields. The hydromantic limit layer can be viewed in a couple of specialized frameworks using fluid metallics as well as plasma streams similar to the cross-over of the attractive fields. For example, through Lorentz forces, the control of a stream might be recognized. Recently, a few research articles have managed the limit layer stream issue by extending the surface in the navigated stream under the effect of the magnetic fields [1-8]. These investigations of fluid over an extending sheet are a basic problem in various applications in mechanical fields, for example, polymer sheets and the strand ejection of polymers to the wind-up 
roller, for which a faraway limited separation is then arranged. A quantity of studies has discussed the limit layer problems past an extending surface into a region in the vicinity and the level of attractive degree [9-15].

The additions in everyday warm conductibility have a basic effect on upgrading the warmth transport behaviors of fluids. From beginning to end, using a few assembling tools, warmth ought to be conflated, colonial, and incited beginning with the singular strategy stream, then the next, and transformed to the critical endeavor as a mechanical prerequisite. Those techniques are given a source of energy deterioration and treat fluid warming as refrigeration. These improvements related to warming up (or refrigerating) within the mechanical technique might cause protection of imperativeness, a decrease in activity time, an increment in warming assessment, and a lengthening of the working device's existence. The progression of the predominant warm conductivity of the fluid for the improvement of the transformation of heat is being pursued at the moment. Thus, the presence of raised warmth stream structures causes basic enthusiasm for the request to progress toward the improvement of the exchange of heat. Researchers have endeavored to specifically improve the low warm conductibility of the ordinary transform of the heat of fluids utilizing the macroscopic effective medium theory (EMT) presented by Maxwell [16] in 1873 for the suitable properties of a blend.

Nanoparticles are created utilizing distinct materials, such as carbide ceramic ( $\mathrm{Sic}$ and Tic), metal nitride $(\mathrm{AiN}$ and $\mathrm{SiN})$, oxide care-mics $\left(\mathrm{Al}_{2} \mathrm{O}_{3}\right.$ and $\left.\mathrm{CuO}\right)$, metals $(\mathrm{Cu}, \mathrm{Ag}$ and $A u$ ), carbon in particular (for example, precious stones (diamond), carbon nanotubes, graphite, and fullerene), and functionalized nanoparticles [17-22]. A few preliminary exploratory outcomes [23] have shown, for example, an increase in the conductivity of heat of generally $60 \%$, as it might be obtained for nanofluid including water $\left(\mathrm{H}_{2} \mathrm{O}\right)$ and $5 \%$ of copper oxide $(\mathrm{CuO})$ nanoparticles. Masuda et al. [24] exhibited that the trademark achievement of nanofluids is the conductivity of the heat upgrade phenomenon. As of late, Buongiorno examined the effective seven-slip system to perceive the inertia, Brownian movement, thermophoresis, Magnus impact, bottle dissemination, fluid seepage, and attraction (gravitation) settling. He achieved a cultivated review of the convective vehicle in the nanofluids. A recent examination [25] observed that an upgrade in the transformation of heat within sight of nanoparticles can assume an imperative part in different physical calculations [26]. Shafiq et al. [27] discussed an enhancement in thermal energy and the diffusion of mass by inserting nanoparticles toward an expanding surface containing microorganisms via the zero mass flux condition. Shafiq et al. [28] studied thermal aspects using slip and convective conditions by inserting nanoparticles along with the Darcy-Forchheimer law. Rasool et al. [29] performed experiments related to entropy generation in MHD Williamson liquid, considering the effects of chemical reactions within entropy generation toward a porous surface. Abo-Dahab et al. [30] discussed the magnetohydrodynamic flow in Casson material over a porous surface. Mebarek-Oudina et al. [31] studied an increase in thermal energy using hybrid nanoparticles and nanoparticles toward a porous heated enclosure. Swain et al. [32] used an exponentially porous surface to analyze the flow and thermal characterizations considering nanoparticles via slip conditions. Some recent contributions covering numerous physical aspects and computational approaches have been reported in [33-37].

The impact of inclined MHD nanofluid provoked by a stretching sheet embedded in a porous medium was investigated. Two types of nanoparticles, copper and aluminum oxide, were used, with water as the base fluid. Similarity transformations were used to convert the partial differential equations into a set of ordinary differential equations. Such a developed problem has not been investigated yet. The current work is organized as follows: Section 1 is related to the introduction, and the preparation of the model is explained in Section 2. Section 3 addresses the solution to the problem. Graphical outcomes are discussed in Section 4 . The last section contains the primary consequences of the problem. 


\section{Mathematical Formulation}

Suppose a 2D (two-dimensional), consistent, incompressible progression of a nanofluid over an extending sheet with slip impacts at the surface soaked in a porous medium shown in Figure 1. In this unique situation, water is considered the base liquid, with two types of metal nanoparticles considered to be specific: copper, with the formula $(\mathrm{Cu})$, and aluminum oxide, with the formula $\left(\mathrm{Al}_{2} \mathrm{O}_{3}\right)$. The slanted attractive field (magnetic field) is applied to the y-pivot of solidarity $B_{0}$ with an angle $\gamma$, which is an acute angle that is ordinary to the surface, and the $x$-pivot is parallel to the sheet. Motion into the copper and aluminum oxide over a surface with the movement of the wall was noticed. The effect of the induced magnetic field was ignored. Heat energy characterizations were established in the presence of thermal radiation. Slip conditions were used to analyze flow behavior and thermal aspects. A steady flow and incompressible flow were addressed. Those were to assume the influence of an attractive field that is discredited in correspondence with the upheld attractive limit. However, the applied attractive field typically happens at the surface with the transverse attractive field at $\gamma=\frac{\pi}{2}$ i.e., $\operatorname{Sin}\left(\frac{\pi}{2}\right)=1$. The assumptions are listed below.

$>$ Two-dimensional flow for steady and incompressible flows;

$>$ Slip conditions are used;

$>$ Thermal radiation is addressed;

$>$ A constant magnetic field is considered;

$>$ An expanding surface is taken out;

$>$ Two kinds of nanoparticles $(\mathrm{Cu}$ and $\mathrm{Ag})$ in the base fluid $\left(\mathrm{H}_{2} \mathrm{O}\right)$ are inserted in a Newtonian liquid.

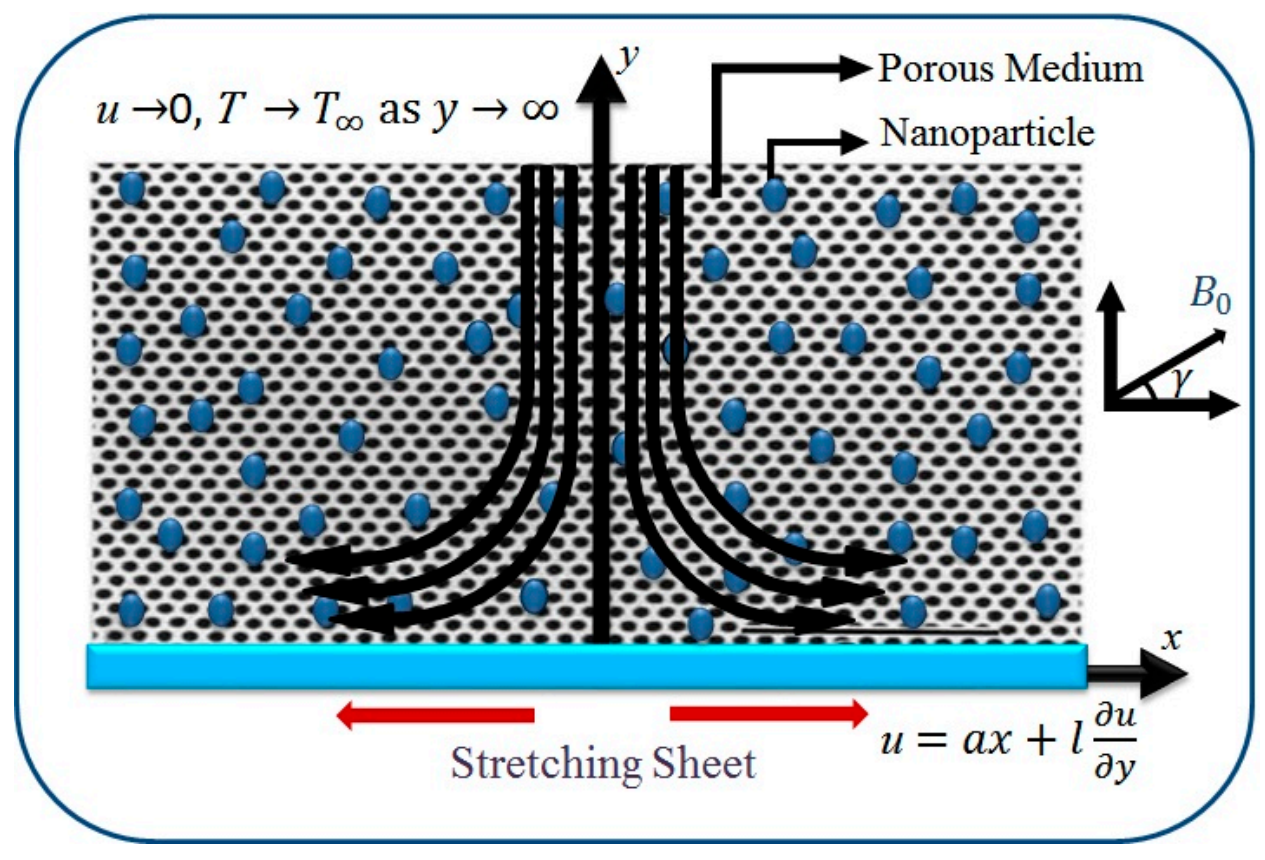

Figure 1. Physical view of the model.

BLA (boundary layer approximations) were used to model the required PDEs, and the PDEs are:

$$
\begin{gathered}
\frac{\partial u}{\partial x}+\frac{\partial v}{\partial y}=0 \\
u \frac{\partial u}{\partial x}+v \frac{\partial v}{\partial y}=\left(1+\frac{1}{\delta}\right) \frac{\mu_{n f}}{\rho_{n f}} \frac{\partial^{2} u}{\partial y^{2}}-\frac{\sigma_{n f} B_{0}^{2}}{\rho_{n f}} u \operatorname{Sin}^{2} \gamma-\frac{\mu_{n f}}{\rho_{n f}} \frac{u}{k_{p}} \\
u \frac{\partial T}{\partial x}+v \frac{\partial T}{\partial y}=\frac{k_{n f}}{\left(\rho C_{P}\right)_{n f}} \frac{\partial^{2} T}{\partial y^{2}}+\frac{16 \sigma^{*} T_{\infty}^{3}}{3 k_{*}\left(\rho C_{P}\right)_{n f}} \frac{\partial^{2} T}{\partial y^{2}}
\end{gathered}
$$


These are subjected to the boundary conditions:

$$
\begin{aligned}
u=a x+l \frac{\partial u}{\partial y}, v & =v_{w}, T_{w}=T_{\infty}+A\left(\frac{x}{l}\right)^{2} \text { when } y=0, \\
u & \rightarrow 0, T \rightarrow T_{\infty} \text { at } y \rightarrow \infty
\end{aligned}
$$

The variation in variables of the current study is:

$$
\begin{gathered}
u=a x f^{\prime}(\eta), v=-\left(a v_{f}\right)^{\frac{1}{2}} f(\eta), \eta=y\left(a v_{f}\right)^{\frac{1}{2}}, \\
\theta(\eta)=\frac{T-T_{\infty}}{T_{w}-T_{\infty}}
\end{gathered}
$$

Applying transformation (5) produces the following:

$$
\left.\begin{array}{c}
\frac{1}{A_{1} A_{2}}\left(1+\frac{1}{\delta}\right) f^{\prime \prime \prime}+f f^{\prime \prime}+\left(f^{\prime} f^{\prime}-\frac{A_{4}}{A_{2}} M \operatorname{Sin}^{2} \gamma f^{\prime}\right)-\frac{1}{A_{1} A_{2}} K_{I} f^{\prime}=0 \\
f=0, f^{\prime}(0)=1+\frac{\beta}{A_{2}} f^{\prime \prime}(0), f \prime(\infty) \rightarrow 0 \\
\left(1+\frac{4 A_{5}}{3 N}\right) \theta^{\prime \prime}+\frac{A_{3}}{A_{5}} \operatorname{Pr} f \theta^{\prime}-2 \frac{A_{3}}{A_{5}} \operatorname{Pr} f^{\prime} \theta=0 \\
\theta(0)=1, \theta(\infty) \rightarrow \infty
\end{array}\right\},
$$

The associated correlations among nanoparticles are:

$$
\begin{aligned}
& A_{1}=(1-\phi)^{2.5}, A_{2}=\left(1-\phi+\frac{\left(\rho C_{P}\right)_{s}}{\left(\rho C_{P}\right)_{f}} \phi\right), A_{3}=\left(1-\phi+\frac{\rho_{s}}{\rho_{f}} \phi\right), \\
& A_{4}=\left(1+\frac{\left(\frac{\sigma_{s}}{\sigma_{f}}-1\right) \phi}{\left(\frac{\sigma_{s}}{\sigma_{f}}+2\right)-\phi\left(\frac{\sigma_{s}}{\sigma_{f}}-1\right)}\right), A_{5}=\frac{K_{s}+2 K_{f}-2 \phi\left(K_{f}-K_{s}\right)}{K_{s}+2 K_{f}-\phi\left(K_{f}-K_{s}\right)}, L=\frac{\beta}{A_{1}} .
\end{aligned}
$$

The Hartmann number, slip parameter, and Prandtl number are captured as:

$$
M=\frac{\left(B_{0}\right)^{2} \sigma_{f}}{a \rho_{f}}, \beta=\frac{l}{\left(\frac{a}{v_{f}}\right)^{1 / 2}}, \operatorname{Pr}=\frac{C_{P} \mu}{k}, N=\frac{k_{*} k_{n f}}{\left(T_{\infty}\right)^{3} 4 \sigma^{*}}, K_{I}=\frac{v_{f}}{k_{p} a} .
$$

The skin friction coefficient and rate of heat transfer are modeled as:

$$
\begin{gathered}
C_{f}=\frac{\tau_{w}}{\rho_{f}\left(u_{w}\right)^{2}}, C_{f}=\frac{R e_{x}^{-1 / 2}}{A_{1}} f^{\prime \prime}(0), \\
N_{u}=\frac{x q_{w}}{k_{f}\left(T_{w}-T_{\infty}\right)}, N u_{x} R e_{x}^{\frac{1}{2}}=-\left(\frac{K_{n f}}{K_{f}}+\frac{4}{3 N}\right) \theta^{\prime}(0) .
\end{gathered}
$$

The local Reynolds number is $\operatorname{Re}\left(=\frac{x u_{w}}{v_{f}}\right)$.

\section{Exact Solution of Problem}

The exact solution was implemented with Equations (6)-(7) using MATLAB. The required function is considered here:

$$
f(\eta)=\frac{X-X e^{-\alpha \eta}}{\alpha}
$$

$X=\frac{1}{\beta \alpha+1}$, and $\alpha=\frac{1}{6} \frac{1}{\beta}\left(-72 \mathrm{MA}_{1} \beta^{2} \cos (\theta)^{2}+72 \mathrm{MA}_{1} \beta^{2}+108 \mathrm{~A}_{1} \beta^{2} \mathrm{~A}_{2}-8+12 \sqrt{3}\left(\mathrm{~A}_{1}\right.\right.$ $\left(4 \mathrm{M}^{3} A_{1}^{2} \beta^{4} \cos (\theta)^{6}-12 \mathrm{M}^{3} A_{1}^{2} \beta^{4} \cos (\theta)^{4}+8 \mathrm{M}^{2} \mathrm{~A}_{1} \beta^{4} \cos (\theta)^{2}+12 \mathrm{M}^{3} A_{1}^{2} \beta^{4} \cos (\theta)^{2}-16 \mathrm{M}^{2} \mathrm{~A}_{1} \beta^{2}\right.$ $\cos (\theta)^{2}+4 \cos (\theta)^{2} \mathrm{M}-4 \mathrm{M}^{3} A_{1}^{2} \beta^{4}+8 \mathrm{M}^{2} \mathrm{~A}_{1} \beta^{2}-4 \mathrm{M}-36 \mathrm{MA}_{1} \beta^{2} \cos (\theta)^{2} \mathrm{~A}_{2}+36 \mathrm{MA}_{1} \beta^{2} \mathrm{~A}_{2}$ $\left.\left.\left.+27 \mathrm{~A}_{1} \beta^{2} A_{2}^{2}-4 \mathrm{~A}_{2}\right)\right)^{1 / 2} \beta\right)^{1 / 3}-\frac{2}{3}\left(3 \mathrm{MA}_{1} \beta^{2} \cos (\theta)^{2}-3 \mathrm{MA}_{1} \beta^{2}-1\right) /\left(\beta\left(-72 \mathrm{MA}_{1} \beta^{2} \cos \right.\right.$ $(\theta)^{2}+72 \mathrm{MA}_{1} \beta^{2}+108 \mathrm{~A}_{1} \beta^{2} \mathrm{~A}_{2}-8+12 \sqrt{3}\left(\mathrm{~A}_{1}\left(4 \mathrm{M}^{3} A_{1}^{2} \beta^{4} \cos (\theta)^{6}-12 \mathrm{M}^{3} A_{1}^{2} \beta^{4} \cos (\theta)^{4}\right.\right.$ $+8 \mathrm{M}^{2} \mathrm{~A}_{1} \beta^{4} \cos (\theta)^{2}+12 \mathrm{M}^{3} A_{1}^{2} \beta^{4} \cos (\theta)^{2}-16 \mathrm{M}^{2} \mathrm{~A}_{1} \beta^{2} \cos (\theta)^{2}+4 \cos (\theta)^{2} \mathrm{M}-4 \mathrm{M}^{3} A_{1}^{2} \beta^{4}+$ 
$\left.\left.\left.8 \mathrm{M}^{2} \mathrm{~A}_{1} \beta^{2}-4 \mathrm{M}-36 \mathrm{MA}_{1} \beta^{2} \cos (\theta)^{2} \mathrm{~A}_{2}+36 \mathrm{MA}_{1} \beta^{2} \mathrm{~A}_{2}+27 \mathrm{~A}_{1} \beta^{2} A_{2}^{2}-4 \mathrm{~A}_{2}\right)\right)^{1 / 2} \beta\right)^{1 / 3}-$ $\frac{1}{3 \beta} \frac{1}{6} \frac{1}{\beta}\left(-72 \mathrm{MA}_{1} \beta^{2} \cos (\theta)^{2}+72 \mathrm{MA}_{1} \beta^{2}+108 \mathrm{~A}_{1} \beta^{2} \mathrm{~A}_{2}-8+12 \sqrt{3}\left(\mathrm{~A}_{1}\left(4 \mathrm{M}^{3} A_{1}^{2} \beta^{4}\right.\right.\right.$ $\cos (\theta)^{6} 12 \mathrm{M}^{3} A_{1}^{2} \beta^{4} \cos (\theta)^{4}+8 \mathrm{M}^{2} \mathrm{~A}_{1} \beta^{4} \cos (\theta)^{2}+12 \mathrm{M}^{3} A_{1}^{2} \beta^{4} \cos (\theta)^{2}-16 \mathrm{M}^{2} \mathrm{~A}_{1} \beta^{2} \cos (\theta)^{2}+$ $4 \cos (\theta)^{2} \mathrm{M}-4 \mathrm{M}^{3} A_{1}^{2} \beta^{4}+8 \mathrm{M}^{2} \mathrm{~A}_{1} \beta^{2}-4 \mathrm{M}-36 \mathrm{MA}_{1} \beta^{2} \cos (\theta)^{2} \mathrm{~A}_{2}+36 \mathrm{MA}_{1} \beta^{2} \mathrm{~A}_{2}+27 \mathrm{~A}_{1} \beta^{2} A_{2}^{2}$ $\left.\left.\left.-4 \mathrm{~A}_{2}\right)\right)^{1 / 2} \beta\right)^{1 / 3}-\frac{2}{3}\left(3 \mathrm{MA}_{1} \beta^{2} \cos (\theta)^{2}-3 \mathrm{MA}_{1} \beta^{2}-1\right) /\left(\beta\left(-72 \mathrm{MA}_{1} \beta^{2} \cos (\theta)^{2}+72 \mathrm{MA}_{1} \beta^{2}\right.\right.$ $+108 \mathrm{~A}_{1} \beta^{2} \mathrm{~A}_{2}-8+12 \sqrt{3}\left(\mathrm{~A}_{1}\left(4 \mathrm{M}^{3} A_{1}^{2} \beta^{4} \cos (\theta)^{6}-12 \mathrm{M}^{3} A_{1}^{2} \beta^{4} \cos (\theta)^{4}+8 \mathrm{M}^{2} \mathrm{~A}_{1} \beta^{4} \cos (\theta)^{2}\right.\right.$ $+12 \mathrm{M}^{3} A_{1}^{2} \beta^{4} \cos (\theta)^{2}-16 \mathrm{M}^{2} \mathrm{~A}_{1} \beta^{2} \cos (\theta)^{2}+4 \cos (\theta)^{2} \mathrm{M}-4 \mathrm{M}^{3} A_{1}^{2} \beta^{4}+8 \mathrm{M}^{2} \mathrm{~A}_{1} \beta^{2}-4 \mathrm{M}-$ $\left.\left.\left.36 \mathrm{MA}_{1} \beta^{2} \cos (\theta)^{2} \mathrm{~A}_{2}+36 \mathrm{MA}_{1} \beta^{2} \mathrm{~A}_{2}+27 \mathrm{~A}_{1} \beta^{2} A_{2}^{2}-4 \mathrm{~A}_{2}\right)\right)^{1 / 2} \beta\right)^{1 / 3}-\frac{1}{3 \beta} \frac{1}{6} \frac{1}{K_{1} \beta}\left(\left(-72 \mathrm{~K}_{1} \beta^{2}\right.\right.$ $\cos (\theta)^{2} \mathrm{~A}_{1} \mathrm{M}+108 \mathrm{~K}_{1} \beta^{2} \mathrm{~A}_{1} \mathrm{~A}_{2}+72 \mathrm{~K}_{1} \beta^{2} \mathrm{~A}_{1} \mathrm{M}+72 \beta^{2} \mathrm{~A}_{1} \mathrm{~A}_{2}+12 \sqrt{3}\left(\frac{1}{K_{1}}\left(\mathrm{~A}_{1}\left(4 K_{1}^{3} \beta^{4} \cos (\theta)^{6} A_{1}^{2} \mathrm{M}^{3}\right.\right.\right.$ $-12 K_{1}^{3} \beta^{4} \cos (\theta)^{4} A_{1}^{2} \mathrm{M}^{3}-12 K_{1}^{2} \beta^{4} \cos (\theta)^{4} A_{1}^{2} \mathrm{~A}_{2} \mathrm{M}^{2}+12 K_{1}^{3} \beta^{4} \cos (\theta)^{2} A_{1}^{2} \mathrm{M}^{3}+24 K_{1}^{2} \beta^{4} \cos (\theta)^{2}$ $A_{1}^{2} \mathrm{~A}_{2} \mathrm{M}^{2}-4 K_{1}^{3} \beta^{4} A_{1}^{2} \mathrm{M}^{3}+8 K_{1}^{3} \beta^{2} \cos (\theta)^{4} \mathrm{~A}_{1} \mathrm{M}^{2}+12 \mathrm{~K}_{1} \beta^{4} \cos (\theta)^{2} A_{1}^{2} A_{2}^{2} \mathrm{M}-12 K_{1}^{2} \beta^{4} A_{1}^{2} \mathrm{~A}_{2} \mathrm{M}^{2}$ $-36 K_{1}^{3} \beta^{2} \cos (\theta)^{2} \mathrm{~A}_{1} \mathrm{~A}_{2} \mathrm{M}-16 K_{1}^{3} \beta^{2} \cos (\theta)^{2} \mathrm{~A}_{1} \mathrm{M}^{2}-12 \mathrm{~K}_{1} \beta^{4} A_{1}^{2} A_{2}^{2} \mathrm{M}-36 K_{1}^{2} \beta^{2} \cos (\theta)^{2} \mathrm{~A}_{1} \mathrm{~A}_{2} \mathrm{M}$ $-4 \beta^{4} A_{1}^{2} A_{2}^{3}+27 K_{1}^{3} \beta^{2} A_{1} A_{2}^{2}+36 K_{1}^{3} \beta^{2} \mathrm{~A}_{1} \mathrm{~A}_{2} \mathrm{M}+8 K_{1}^{3} \beta^{2} \mathrm{~A}_{1} \mathrm{M}^{2}+36 K_{1}^{2} \beta^{2} A_{1} A_{2}^{2}+16 K_{1}^{2} \beta^{2} \mathrm{~A}_{1} \mathrm{~A}_{2} \mathrm{M}$ $\left.\left.\left.\left.\left.+4 K_{1}^{3} \cos (\theta)^{2} \mathrm{M}+8 \mathrm{~K}_{1} \beta^{2} \mathrm{~A}_{1} A_{2}^{2}-4 K_{1}^{3} \mathrm{~A}_{2}-4 K_{1}^{3} \mathrm{M}-4 K_{1}^{2} \mathrm{~A}_{2}\right)\right)\right)^{1 / 2} \beta-8 \mathrm{~K}_{1}\right) K_{1}^{2}\right)^{1 / 3}-\frac{2}{3}\left(3 \mathrm{~K}_{1} \beta^{2}\right.$ $\left.\cos (\theta)^{2} \mathrm{~A}_{1} \mathrm{M}-3 \mathrm{~K}_{1} \beta^{2} \mathrm{~A}_{1} \mathrm{M}-3 \beta^{2} \mathrm{~A}_{1} \mathrm{~A}_{2}-\mathrm{K}_{1}\right) /\left(\beta\left(-72 \mathrm{~K}_{1} \beta^{2} \cos (\theta)^{2} \mathrm{~A}_{1} \mathrm{M}+108 \mathrm{~K}_{1} \beta^{2} \mathrm{~A}_{1} \mathrm{~A}_{2}+\right.\right.$ $72 \mathrm{~K}_{1} \beta^{2} \mathrm{~A}_{1} \mathrm{M}+72 \beta^{2} \mathrm{~A}_{1} \mathrm{~A}_{2}+12 \sqrt{3}\left(\frac{1}{K_{1}}\left(\mathrm{~A}_{1}\left(4 K_{1}^{3} \beta^{4} \cos (\theta)^{6} A_{1}^{2} \mathrm{M}^{3}-12 K_{1}^{3} \beta^{4} \cos (\theta)^{4} A_{1}^{2} \mathrm{M}^{3}-\right.\right.\right.$ $12 K_{1}^{2} \beta^{4} \cos (\theta)^{4} A_{1}^{2} \mathrm{~A}_{2} \mathrm{M}^{2}+12 K_{1}^{3} \beta^{4} \cos (\theta)^{2} A_{1}^{2} \mathrm{M}^{3}+24 K_{1}^{2} \beta^{4} \cos (\theta)^{2} A_{1}^{2} \mathrm{~A}_{2} \mathrm{M}^{2}-4 K_{1}^{3} \beta^{4} A_{1}^{2} \mathrm{M}^{3}+$ $8 K_{1}^{3} \beta^{2} \cos (\theta)^{4} \mathrm{~A}_{1} \mathrm{M}^{2}+12 \mathrm{~K}_{1} \beta^{4} \cos (\theta)^{2} A_{1}^{2} A_{2}^{2} \mathrm{M}-12 K_{1}^{2} \beta^{4} A_{1}^{2} \mathrm{~A}_{2} \mathrm{M}^{2}-36 K_{1}^{3} \beta^{2} \cos (\theta)^{2} \mathrm{~A}_{1} \mathrm{~A}_{2} \mathrm{M}-$ $16 K_{1}^{3} \beta^{2} \cos (\theta)^{2} \mathrm{~A}_{1} \mathrm{M}^{2}-12 \mathrm{~K}_{1} \beta^{4} A_{1}^{2} A_{2}^{2} \mathrm{M}-36 K_{1}^{2} \beta^{2} \cos (\theta)^{2} \mathrm{~A}_{1} \mathrm{~A}_{2} \mathrm{M}-4 \beta^{4} A_{1}^{2} A_{2}^{3}+27 K_{1}^{3} \beta^{2} A_{1} A_{2}^{2}$ $+36 K_{1}^{3} \beta^{2} \mathrm{~A}_{1} \mathrm{~A}_{2} \mathrm{M}+8 K_{1}^{3} \beta^{2} \mathrm{~A}_{1} \mathrm{M}^{2}+36 K_{1}^{2} \beta^{2} A_{1} A_{2}^{2}+16 K_{1}^{2} \beta^{2} \mathrm{~A}_{1} \mathrm{~A}_{2} \mathrm{M}+4 K_{1}^{3} \cos (\theta)^{2} \mathrm{M}+8 \mathrm{~K}_{1} \beta^{2} \mathrm{~A}_{1}$ $\left.\left.\left.\left.\left.A_{2}^{2}-4 K_{1}^{3} \mathrm{~A}_{2}-4 K_{1}^{3} \mathrm{M}-4 K_{1}^{2} \mathrm{~A}_{2}\right)\right)\right)^{1 / 2} \beta-8 \mathrm{~K}_{1}\right) K_{1}^{2}\right)^{1 / 3}-\frac{1}{3 \beta}$.

\section{Outcomes and Discussion}

The features of MHD provoked by a stretching sheet embedded in a porous medium were captured. In Table 1, the thermo-physical properties of water, and furthermore, each nanoparticle, are introduced in the shaping of the thickness, definite warmth, and warm conductivity. Table 2 presents the comparative analysis. It was recorded that the obtained solution is in full agreement with the findings reported in [37]. Prior to examining the comportment of the compelling profiles, we conducted an examination with the accessible outcomes in this work. It was clearly observed that the outcomes were exact for the preventive case in the examination. Two significant types of nanoparticles-copper, with the formula $C u$, and aluminum oxide - were analyzed inside a base liquid of water. The impact of the nanoparticles' volume portion with the base liquid of water was discussed through the speed and temperature for the recommended surface warmth motion (See Figure $2 a, b)$. The velocity field was decreased by enhancing the value of the permeability parameter, and the opposite behavior was shown in the case of $\mathrm{Al}_{2} \mathrm{O}_{3}$-water, as examined in Figure 2a,b. It can be seen in Figure $3 a$ that an expansion in the nanoparticle volume portion diminished the velocity behaviors of the nanofluid ( $\mathrm{Cu}$-water). Considering $\mathrm{Al}_{2} \mathrm{O}_{3}-$ water, it was discovered that a rise in the nanoparticle volume portion increased the velocity profiles Figure $3 \mathrm{~b}$. The declining role of the velocity profiles was investigated versus the impact of $\beta$, visualized by Figure $4 a, b$. In Figure $4 a, b$, the temperature profile shows the behavior of $\mathrm{Cu}$-water and aluminum dioxide $\mathrm{Al}_{2} \mathrm{O}_{3}$ with contact volume $\phi$ expansion of nanoparticle. Temperature was inclined versus the role of the volume fraction number. The velocity and temperature profile of the nanofluid worked counter to the rising slip state estimate. This process of expanding the sheet may involve only some transmission to the liquid. Figure $5 \mathrm{a}, \mathrm{b}$ separately reflect the impacts of the radiation boundaries on the temperature profiles for $\mathrm{Cu}$-water and $\mathrm{Al}_{2} \mathrm{O}_{3}$-water. It may indicate that the temperature of the radiation boundary $\mathrm{N}$ decreases its power. Figure 6 shows that the physical action and velocity profile decrease and the temperature profile increases progressively for both copper water ( $\mathrm{Cu}$-water) and aluminum oxide water $\left(\mathrm{Al}_{2} \mathrm{O}_{3}-\mathrm{water}\right)$ (Figure 7a,b). Figure 8a,b separately reflect the impacts of the radiation boundaries on the temperature profiles for $\mathrm{Cu}$-water and $\mathrm{Al}_{2} \mathrm{O}_{3}$-water. It may indicate that temperature increases versus $\gamma$. 
Table 1. Thermal properties of $\mathrm{Cu}, \mathrm{Al}_{2} \mathrm{O}_{3}$, and water.

\begin{tabular}{cccc}
\hline Physical Properties & Water & $\boldsymbol{C u}$ & $\mathrm{Al}_{2} \boldsymbol{O}_{3}$ \\
\hline$\rho$ & 997.1 & 8933 & 3970 \\
\hline$C_{P}$ & 4179 & 385 & 765 \\
\hline$K$ & 0.613 & 400 & 40 \\
\hline$P r$ & 6.135 & & $59.6 \times 10^{6}$ \\
\hline$\sigma$ & $5.5 \times 10^{-6}$ & $35 \times 10^{6}$ &
\end{tabular}

Table 2. Comparative study for dimensionless stress.

\begin{tabular}{ccc}
\hline$K_{1}$ & {$[33]$} & Present \\
\hline 0 & -1.167721 & -1.167726 \\
\hline 0.5 & -1.366245 & -1.366218 \\
\hline 1.0 & -1.539056 & -1.539091 \\
\hline 1.5 & -1.694089 & -1.694029 \\
\hline 2.0 & -1.835965 & -1.835947 \\
\hline
\end{tabular}

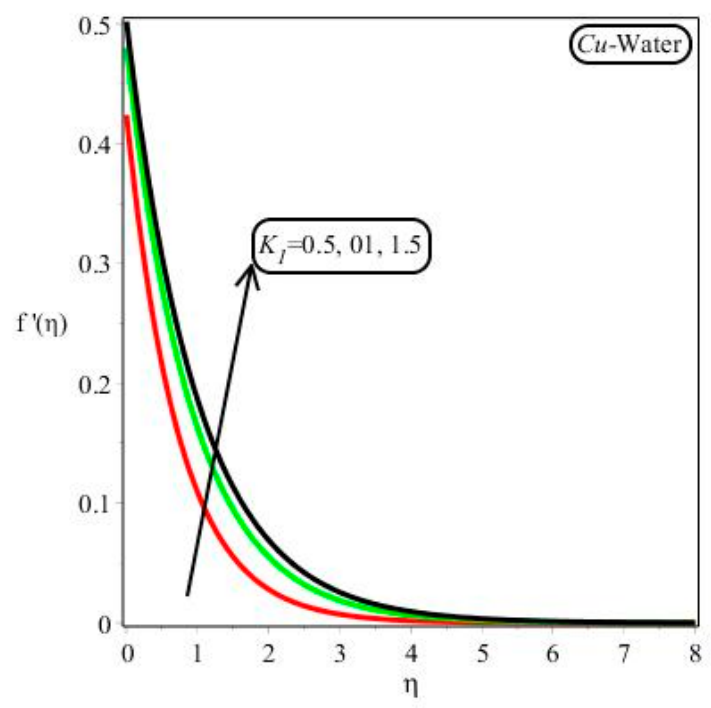

(a)

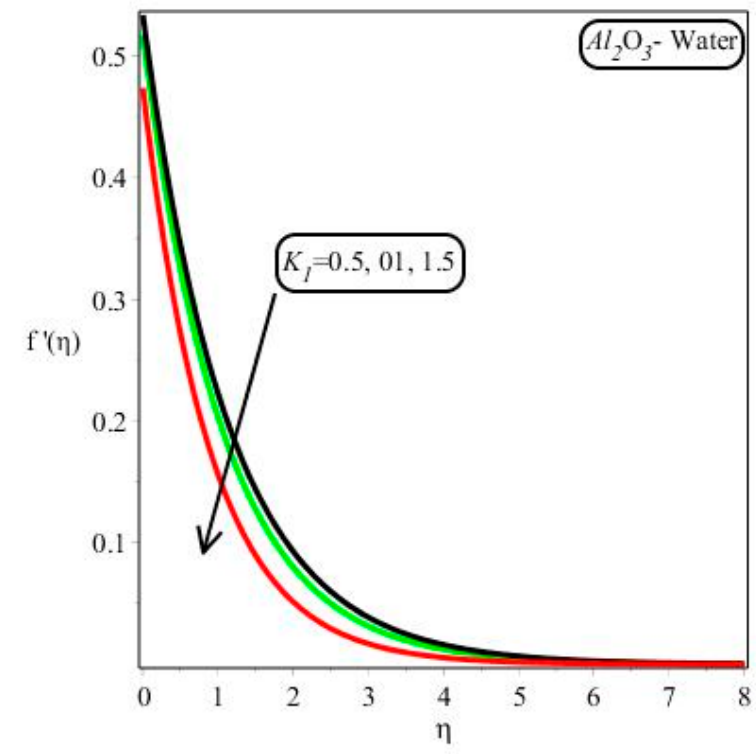

(b)

Figure 2. (a,b) Impact of $K_{1}$ on velocity profile with $\beta=1, \gamma=\pi / 3, \phi=0.2$, and $M=0.2$.

In addition, $\mathrm{Cu}$-water nanofluid was shown to have higher surface friction compared to $\mathrm{Al}_{2} \mathrm{O}_{3}$-water. Figure $9 \mathrm{a}$, $\mathrm{b}$ delineate the effects on the number of surface forces of the attractive boundary versus $K_{I}$, but the opposite treatment was found against $M$ and $\gamma$. The nearby Nusselt number increased, and the estimates of the nanoparticle volume part $\phi$ increments could be seen very well. In Figure 10, $\mathrm{Cu}$-water was found to refer to the rate of warmth movement faster than $\mathrm{Al}_{2} \mathrm{O}_{3}$-water. In Figure 11, the Nusselt neighborhood number was reduced for both $\mathrm{Cu}$-water and $\mathrm{Al}_{2} \mathrm{O}_{3}$-water and for the velocity slip and magnetic limit. Moreover, $\mathrm{Al}_{2} \mathrm{O}_{3}$-water was shown to have a low rate of heat movement relative to $\mathrm{Cu}$-water. The modified point and magnetic boundary consolidated results showed that these restrictions minimized the behavior of the neighborhood Nusselt number. 


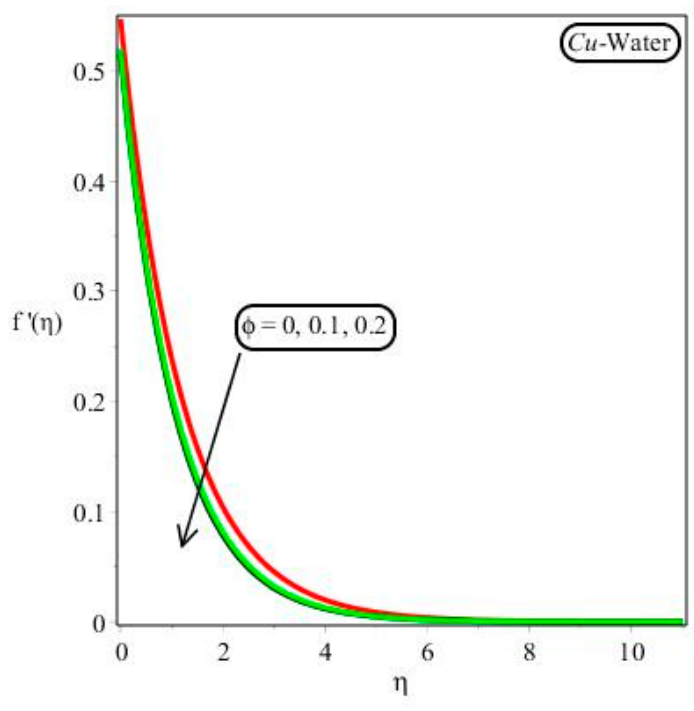

(a)

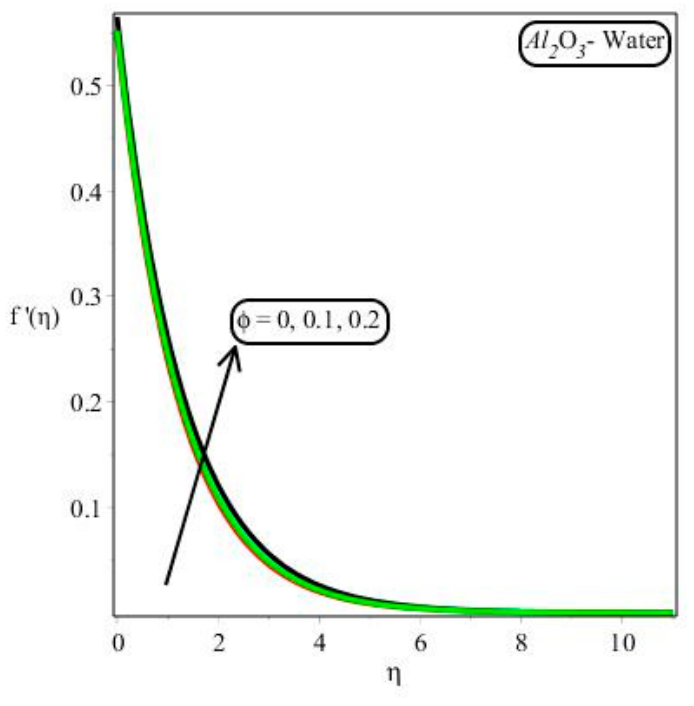

(b)

Figure 3. (a,b) Impact of $\phi$ on velocity profile with $\beta=1, \gamma=\pi / 3, K_{1}=0.7$, and $M=0.2$.

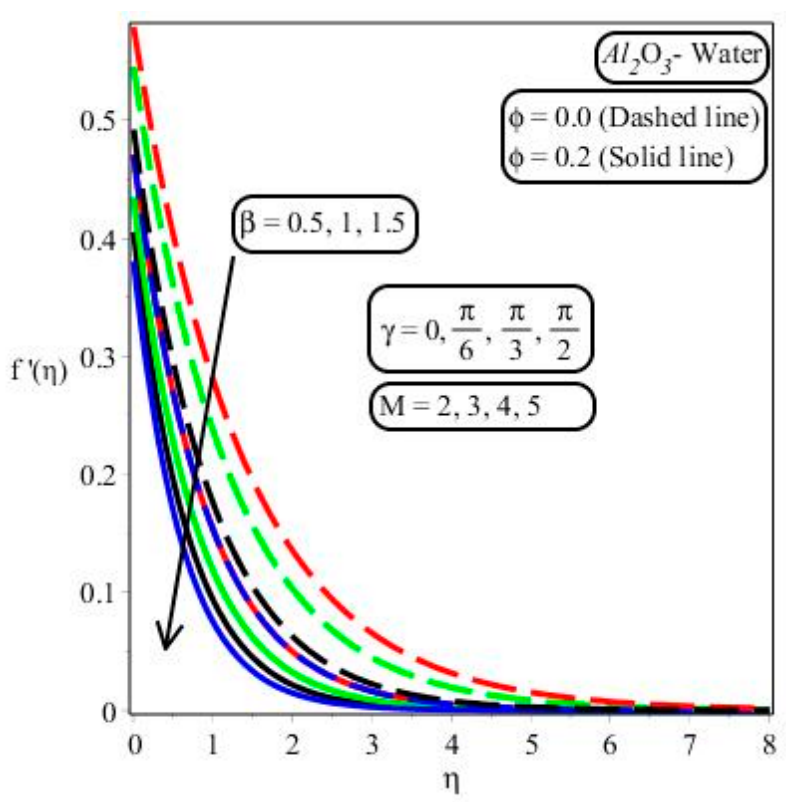

(a)

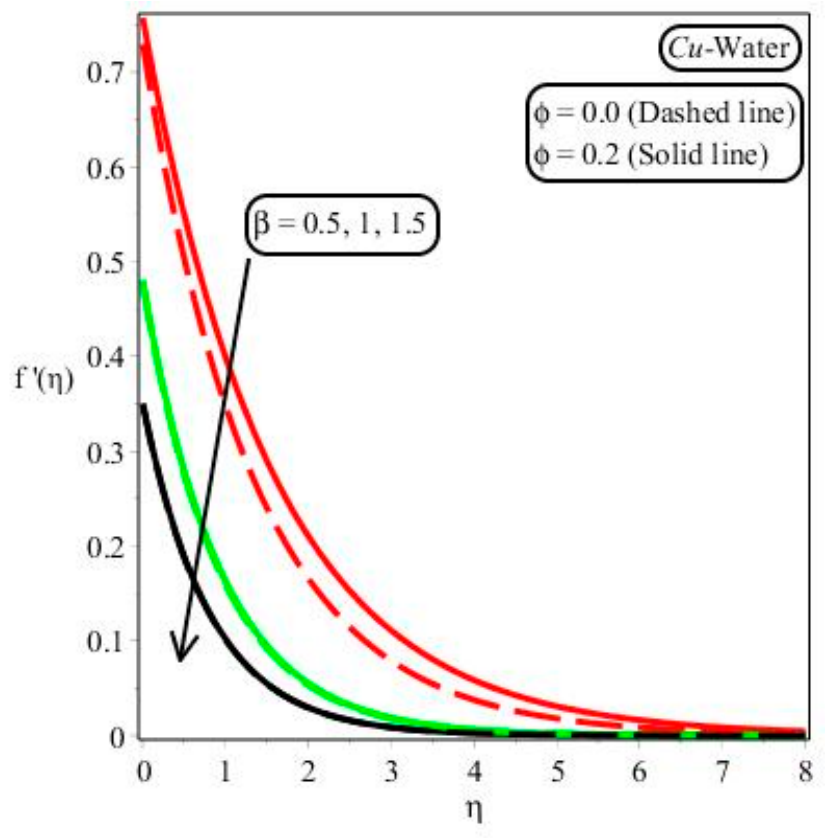

(b)

Figure 4. (a,b) Impact of $\beta$ on velocity profile with $\gamma=\pi / 3, K_{1}=0.7$, and $M=0.2$. 


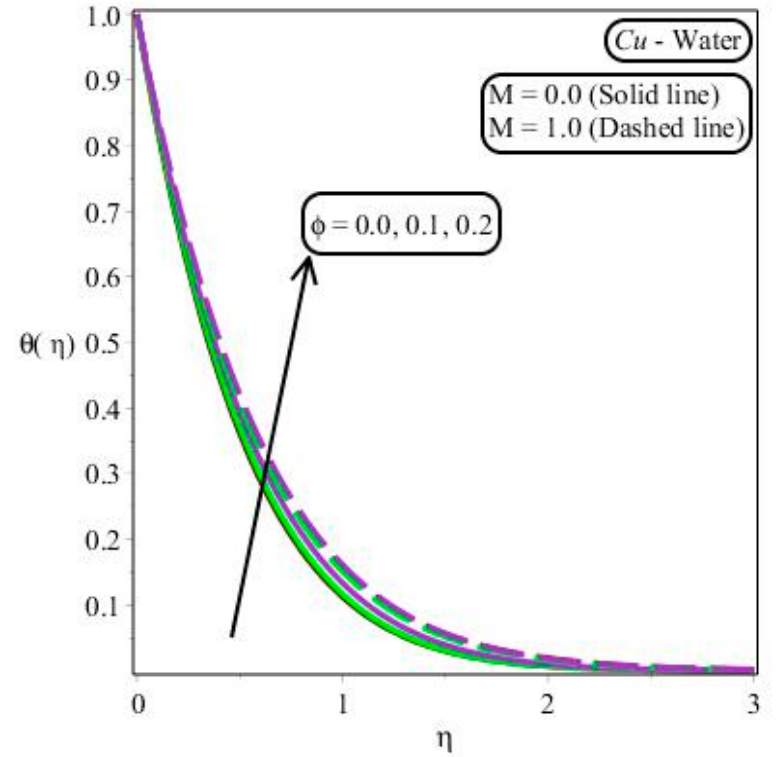

(a)

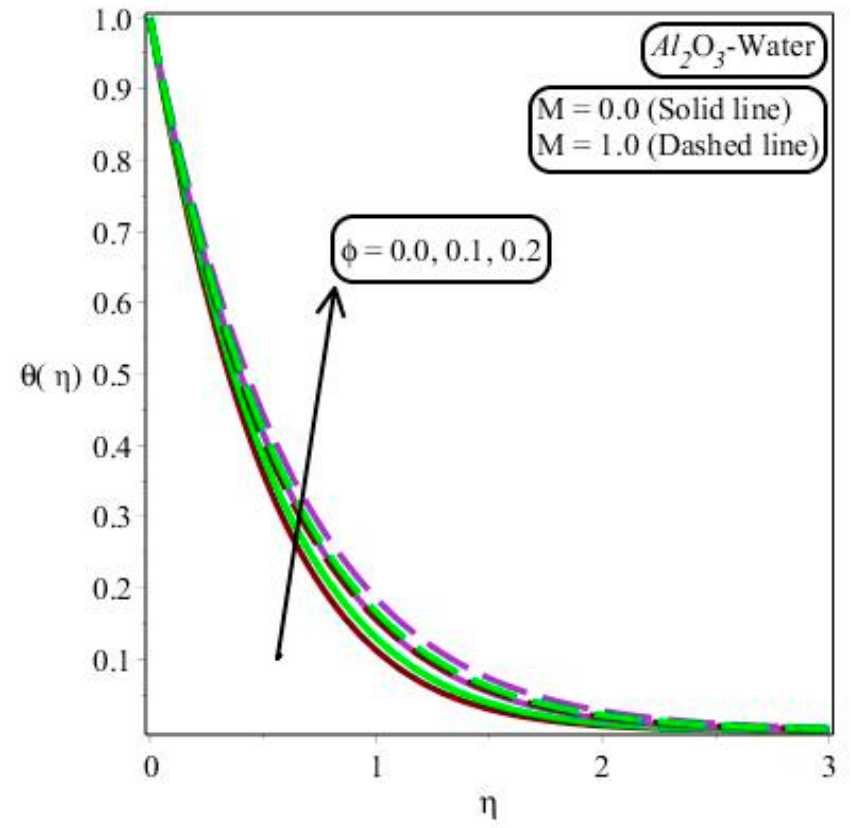

(b)

Figure 5. (a,b) Impact of $K_{1}$ on temperature profile with $\beta=0.7, \gamma=\pi / 4$, and $\varphi=0.2$.

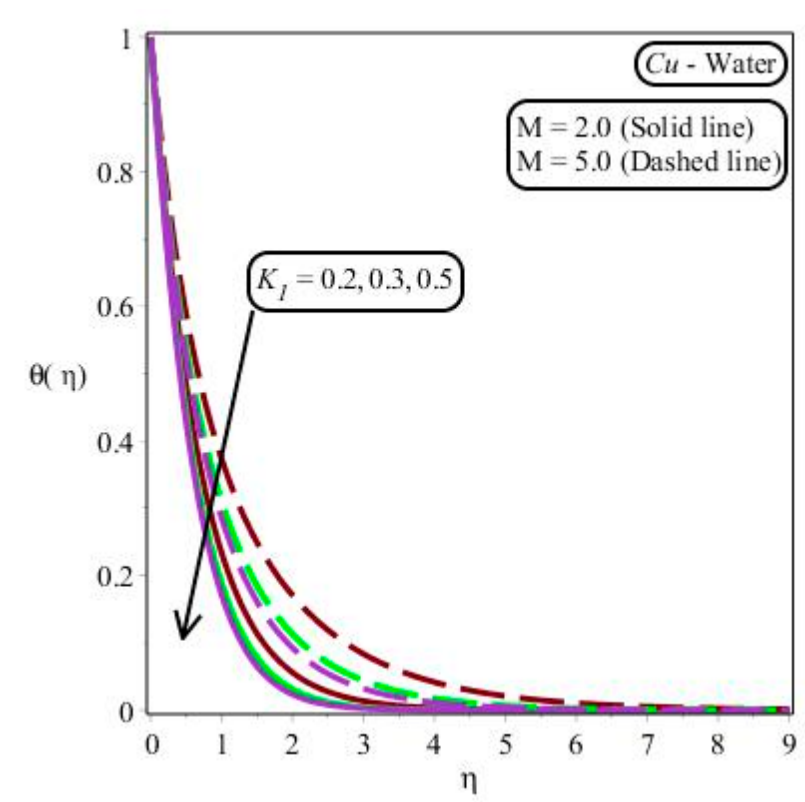

(a)

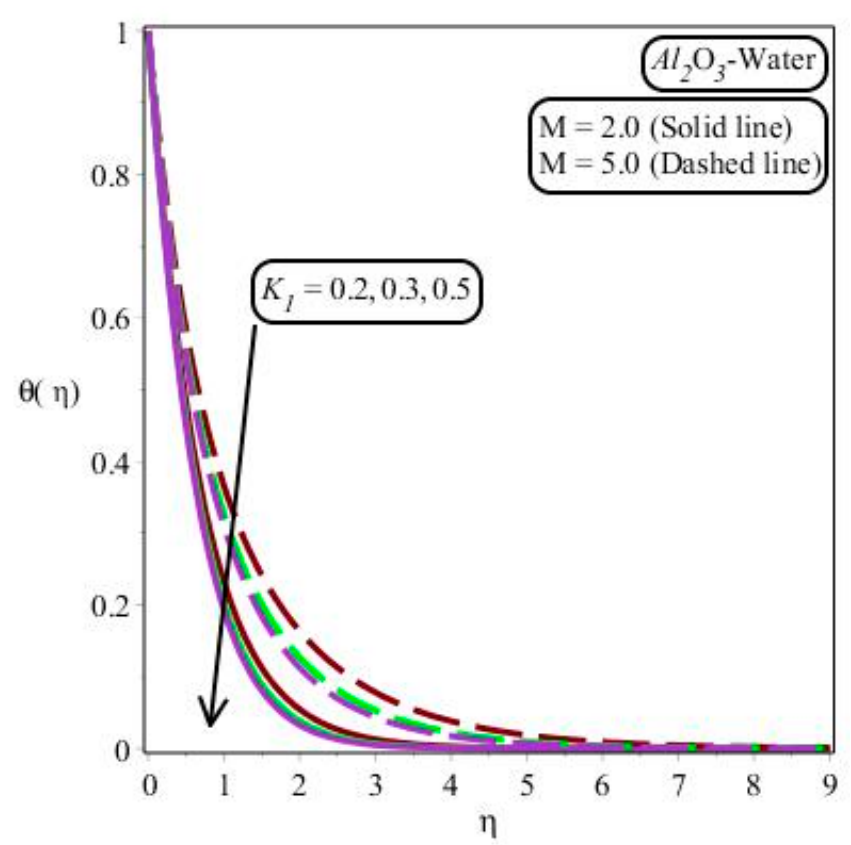

(b)

Figure 6. (a,b) Impact of $\beta$ on temperature profile with $K_{1}=0.7, \gamma=\pi / 4$, and $M=0.2$. 


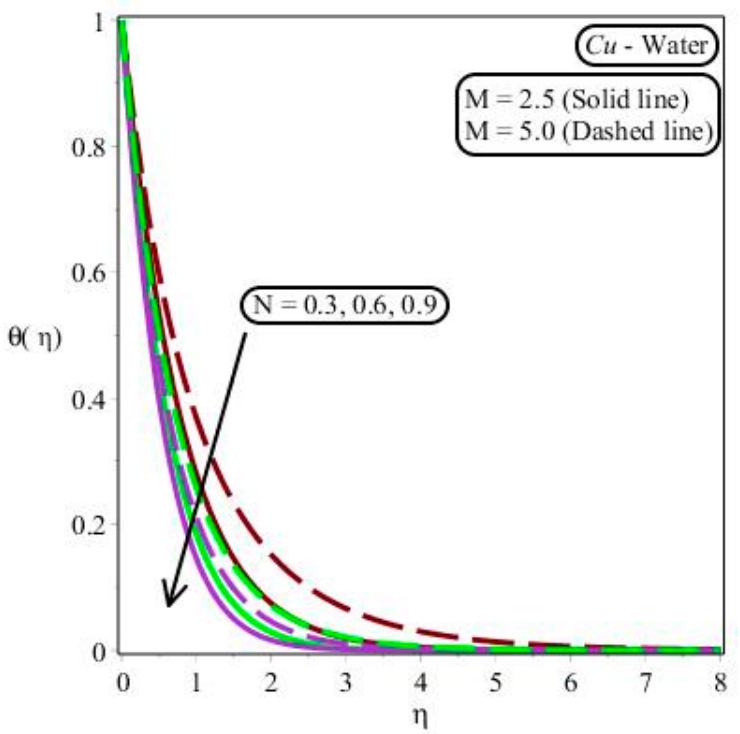

(a)

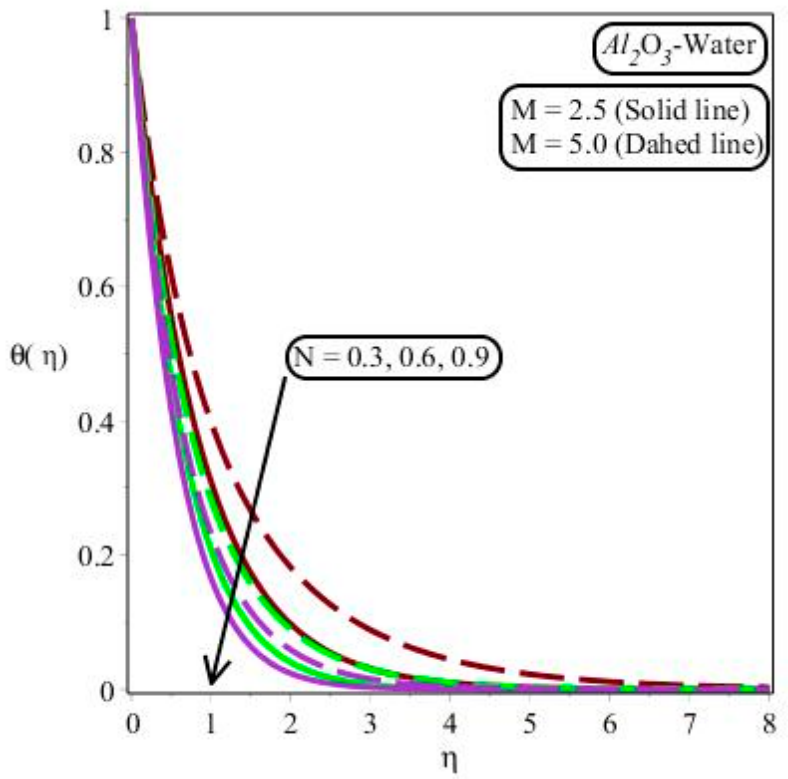

(b)

Figure 7. $(\mathbf{a}, \mathbf{b})$ Impact of $N$ on temperature profile with $K_{1}=0.7, \beta=0.7, \gamma=\pi / 4$, and $\varphi=0.2$.

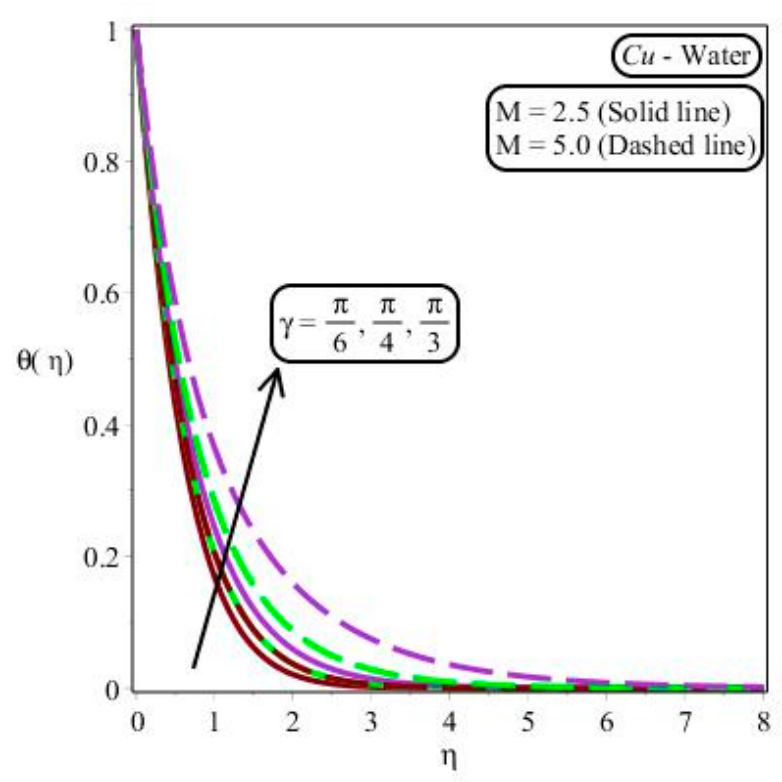

(a)

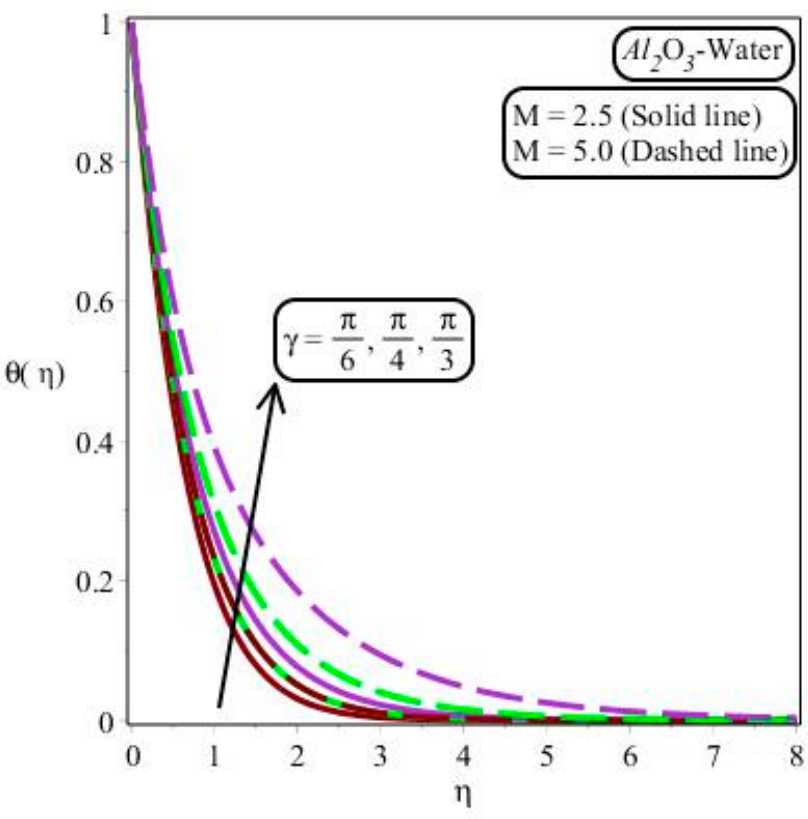

(b)

Figure 8. $(\mathbf{a}, \mathbf{b})$ Impact of $\gamma$ on temperature profile with $\mathrm{K} 1=0.7$ and $\beta=0.7$. 


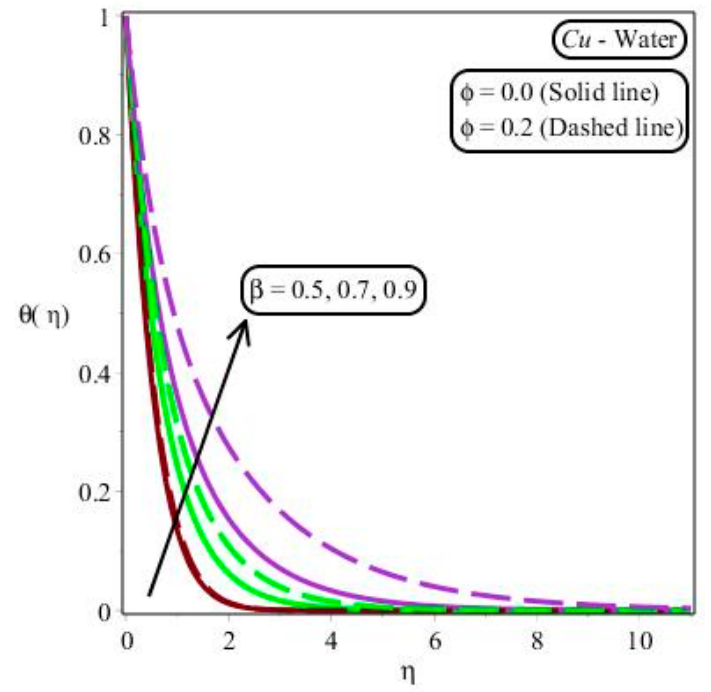

(a)

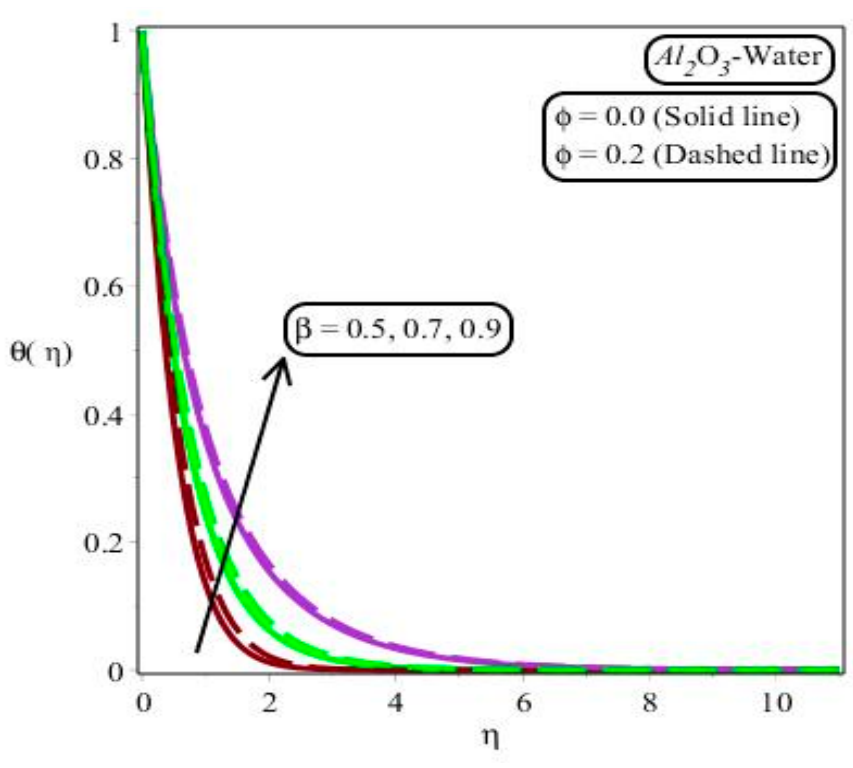

(b)

Figure 9. $(\mathbf{a}, \mathbf{b})$ Impact of $\beta$ on temperature profile with $K_{1}=0.7, \gamma=\pi / 4$, and $M=0.2$.

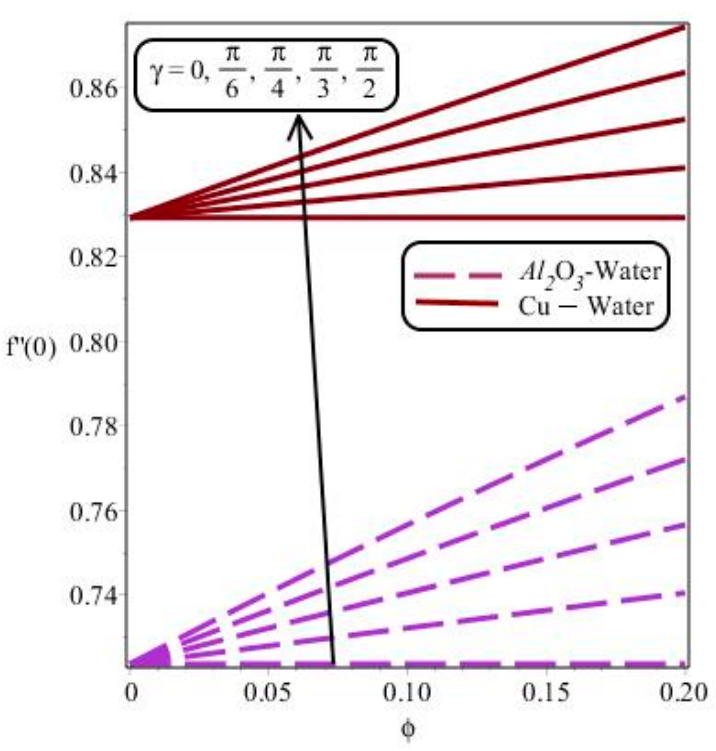

(a)

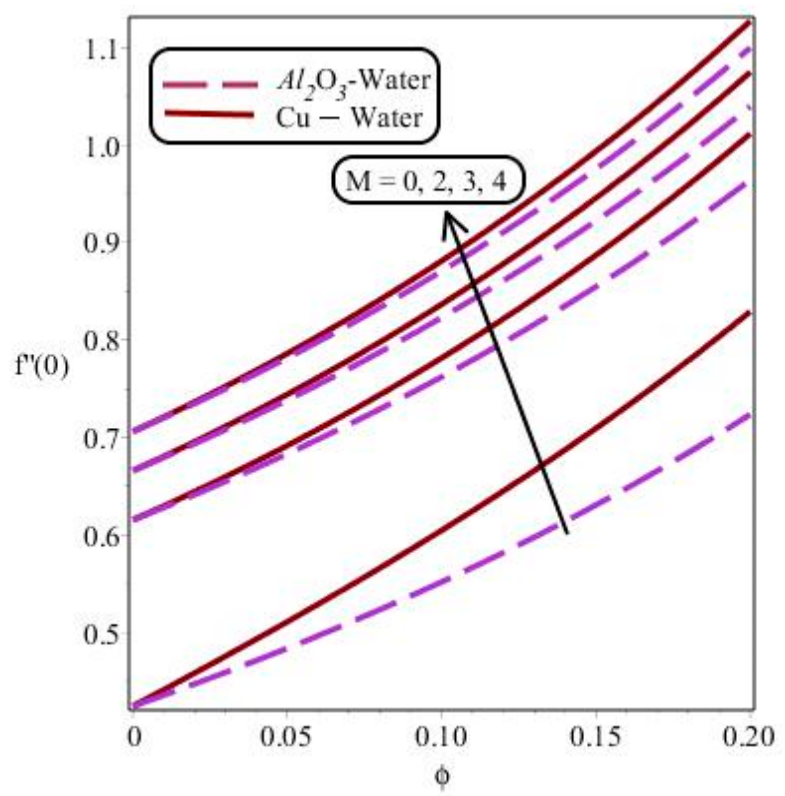

(b)

Figure 10. $(\mathbf{a}, \mathbf{b})$ Impact of $M$ on local skin friction with $K_{1}=0.7, \beta=0.7$, and $\gamma=\pi / 4$. 

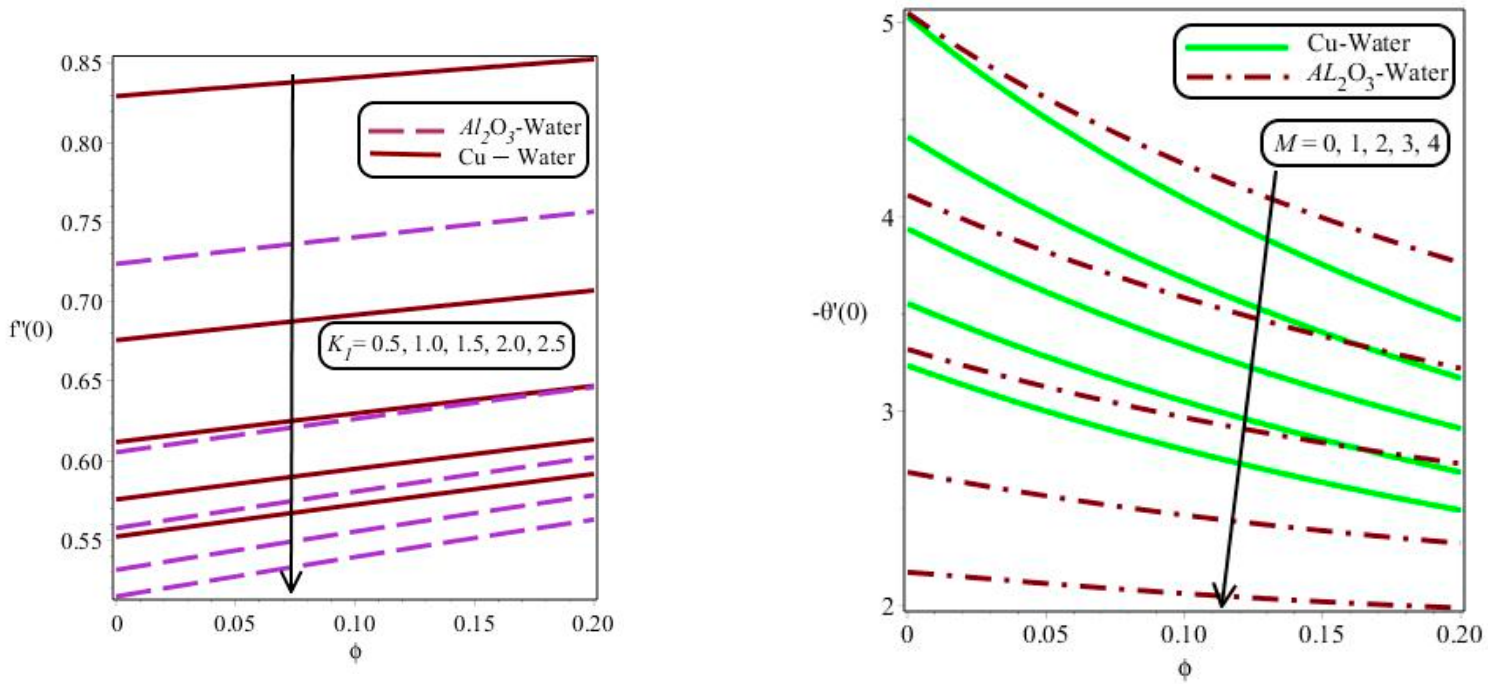

Figure 11. $(\mathbf{a}, \mathbf{b})$ Impact of $M$ and $K_{f}$ on surface force and temperature gradient with $\beta=0.7, N=0.5, K_{1}=0.7$, and $M=0.2$.

\section{Conclusions}

In this article, we studied the effects of the inclined magnetic field, velocity slip, porous medium, and thermal radiation on a nanofluid passed over a cloth for stretching. For the prescribed surface, this study evaluated temperature with two kinds of nanofluids ( $\mathrm{Cu}$-water and $\mathrm{Al}_{2} \mathrm{O}_{3}$-water). The inclined magnetic field obtained appeared enforceable with an aligned angle, in which the aligned angle ranged between 0 and $\pi / 2$. The following were the dominant basic results:

- The nanofluid velocity profile decreased with rising nanofluid values of the fraction rate of the nanoparticle, magnetic parameters, and slip parameter for $\mathrm{Cu}$-water and $\mathrm{Al}_{2} \mathrm{O}_{3}$ water;

- The amount of thermal energy was enhanced against the increment in the volume fraction and slip parameter;

- The impacts of volume fraction were most significant in enhancing the thickness associated with the thermal layers;

- The study of $\mathrm{Cu}$ and $\mathrm{Al}_{2} \mathrm{O}_{3}$ was useful to boost the efficiency of thermal conductivity and thermal energy into particles;

- Thermal radiation brings about a decline in the production of heat energy;

- Reduction was captured in the velocity gradient and temperature gradient against a change in the thermal radiation number;

- The opposite trend was tabulated into motion with respect to the volume fraction number for both cases ( $\mathrm{Cu}$-water and $\mathrm{Al}_{2} \mathrm{O}_{3}$-water);

- Variation in fluid number produces frictional force into the motion of fluid particles.

Author Contributions: Conceptualization, M.S. and S.A.; methodology, S.W.; software, U.N.; validation, M.B.H., M.K. and M.S.; formal analysis, M.K.; investigation, M.S.; resources, U.N.; data curation, S.W.; writing —original draft preparation, U.N.; writing—review and editing, S.W.; visualization, M.K.; supervision, M.S.; project administration, M.S.; funding acquisition, M.K. and S.A. All authors have read and agreed to the published version of the manuscript.

Funding: Research supporting project number (RSP-2021/167), King Saud University, Riyadh, Saudi Arabia.

Institutional Review Board Statement: Not applicable.

Informed Consent Statement: Not applicable.

Data Availability Statement: The datasets generated/produced and/or analyzed during the current study/research are available from the corresponding author on reasonable request. 
Acknowledgments: Research supporting project number (RSP-2021/167), King Saud University, Riyadh, Saudi Arabia.

Conflicts of Interest: The authors declare that they have no known competing financial interests or personal relationships that could have influenced the work reported in this paper.

$\begin{array}{ll}\text { Nomenclature } \\ \text { Symbols } & \text { Used for } \\ v, u & \text { Velocities } \\ \mu & \text { Fluid viscosity } \\ B_{0} & \text { Magnetic field } \\ \sigma^{*} & \text { Electrical conductivity } \\ l & \text { Characteristic length } \\ \infty & \text { Infinity } \\ f & \text { Dimensionless velocity } \\ \varphi & \text { Volume fraction } \\ K & \text { Thermal conductivity } \\ M^{2} & \text { Magnetic number } \\ N u & \text { Nusselt number } \\ \gamma & \text { Inclination angle } \\ k_{s} & \text { Porosity } \\ y, x & \text { Space coordinates } \\ \rho & \text { Fluid density } \\ T & \text { Temperature } \\ C_{P} & \text { Specific heat capacitance } \\ T_{w} & \text { Wall temperature } \\ T_{\infty} & \text { Ambient fluid } \\ \theta & \text { Dimensionless temperature } \\ N & \text { Thermal radiation } \\ P r & \text { Prandtl number } \\ \beta & \text { Flow slip number } \\ R e & \text { Reynolds number } \\ K_{I} & \text { Porous medium number } \\ s & \text { Solid particle } \\ & \end{array}$

\section{References}

1. Hakeem, A.A.; Renuka, P.; Ganesh, N.V.; Kalaivanan, R.; Ganga, B. Influence of inclined Lorentz forces on boundary layer flow of Casson fluid over an impermeable stretching sheet with heat transfer. J. Magn. Magn. Mater. 2016, 401, 354-361. [CrossRef]

2. Makinde, O.D.; Khan, W.A.; Khan, Z.H. Buoyancy effects on MHD stagnation point flow and heat transfer of a nanofluid past a convectively heated stretching/shrinking sheet. Int. J. Heat Mass Transf. 2013, 62, 526-533. [CrossRef]

3. Rahman, M.M.; Eltayeb, I.A. Radiative heat transfer in a hydromagnetic nanofluid past a non-linear stretching surface with convective boundary condition. Meccanica 2013, 48, 601-615. [CrossRef]

4. Akbar, N.S.; Nadeem, S.; Haq, R.U.; Ye, S. MHD stagnation point flow of Carreau fluid toward a permeable shrinking sheet: Dual solutions. Ain Shams Eng. J. 2014, 5, 1233-1239. [CrossRef]

5. Rashidi, M.M.; Ganesh, N.V.; Hakeem, A.A.; Ganga, B. Buoyancy effect on MHD flow of nanofluid over a stretching sheet in the presence of thermal radiation. J. Mol. Liq. 2014, 198, 234-238. [CrossRef]

6. Mastroberardino, A.; Siddique, J.I. Magnetohydrodynamic stagnation flow and heat transfer toward a stretching permeable cylinder. Adv. Mech. Eng. 2014, 6, 419568. [CrossRef]

7. Akbar, N.S.; Ebaid, A.; Khan, Z.H. Numerical analysis of magnetic field effects on Eyring-Powell fluid flow towards a stretching sheet. J. Magn. Magn. Mater. 2015, 382, 355-358. [CrossRef]

8. Chu, Y.M.; Nazir, U.; Sohail, M.; Selim, M.M.; Lee, J.R. Enhancement in thermal energy and solute particles using hybrid nanoparticles by engaging activation energy and chemical reaction over a parabolic surface via finite element approach. Fractal Fract. 2021, 5, 119. [CrossRef]

9. Turkyilmazoglu, M. Analytic heat and mass transfer of the mixed hydrodynamic/thermal slip MHD viscous flow over a stretching sheet. Int. J. Mech. Sci. 2011, 53, 886-896. [CrossRef]

10. Sohail, M.; Nazir, U.; Chu, Y.M.; Al-Kouz, W.; Thounthong, P. Bioconvection phenomenon for the boundary layer flow of magnetohydrodynamic Carreau liquid over a heated disk. Sci. Iran. 2021, 28, 1896-1907.

11. Ellahi, R.; Hassan, M.; Zeeshan, A. Shape effects of nanosize particles in $\mathrm{Cu}-\mathrm{H}_{2} \mathrm{O}$ nanofluid on entropy generation. Int. J. Heat Mass Transf. 2015, 81, 449-456. [CrossRef] 
12. Akbarzadeh, M.; Rashidi, S.; Bovand, M.; Ellahi, R. A sensitivity analysis on thermal and pumping power for the flow of nanofluid inside a wavy channel. J. Mol. Liq. 2016, 220, 1-13. [CrossRef]

13. Zeeshan, A.; Majeed, A.; Ellahi, R. Effect of magnetic dipole on viscous ferro-fluid past a stretching surface with thermal radiation. J. Mol. Liq. 2016, 215, 549-554. [CrossRef]

14. Rahman, S.U.; Ellahi, R.; Nadeem, S.; Zia, Q.Z. Simultaneous effects of nanoparticles and slip on Jeffrey fluid through tapered artery with mild stenosis. J. Mol. Liq. 2016, 218, 484-493. [CrossRef]

15. Nazir, U.; Abu-Hamdeh, N.H.; Nawaz, M.; Alharbi, S.O.; Khan, W. Numerical study of thermal and mass enhancement in the flow of Carreau-Yasuda fluid with hybrid nanoparticles. Case Stud. Therm. Eng. 2021, 27, 101256. [CrossRef]

16. Levin, M.L.; Miller, M.A. Maxwell a treatise on electricity and magnetism. Uspekhi Fiz. Nauk. 1981, 135, 425-440. [CrossRef]

17. Choi, S.U.; Eastman, J.A. Enhancing Thermal Conductivity of Fluids with Nanoparticles; Argonne National Lab.: Lemont, IL, USA, 1995.

18. Wang, X.Q.; Mujumdar, A.S. Heat transfer characteristics of nanofluids: A review. Int. J. Therm. Sci. 2007, 46, 1-19. [CrossRef]

19. Das, S.K.; Choi, S.U.; Patel, H.E. Heat transfer in nanofluids-A review. Heat Transf. Eng. 2006, 27, 3-19. [CrossRef]

20. Cheng, L.; Bandarra Filho, E.P.; Thome, J.R. Nanofluid two-phase flow and thermal physics: A new research frontier of nanotechnology and its challenges. J. Nanosci. Nanotechnol. 2008, 8, 3315-3332. [CrossRef]

21. Eastman, J.A.; Choi, U.S.; Li, S.; Thompson, L.J.; Lee, S. Enhanced thermal conductivity through the development of nanofluids. MRS Online Proc. Libr. 1996, 457. [CrossRef]

22. Haq, R.U.; Noor, N.F.; Khan, Z.H. Numerical simulation of water based magnetite nanoparticles between two parallel disks. Adv. Powder Technol. 2016, 27, 1568-1575. [CrossRef]

23. Khan, Z.H.; Hussain, S.T.; Hammouch, Z. Flow and heat transfer analysis of water and ethylene glycol based Cu nanoparticles between two parallel disks with suction/injection effects. J. Mol. Liq. 2016, 221, 298-304.

24. Masuda, H.; Ebata, A.; Teramae, K.; Hishinuma, N. Alteration of thermal conductivity and viscosity of liquid by dispersing ultra-fine particles. Dispersion of $\mathrm{Al} 2 \mathrm{O} 3, \mathrm{SiO} 2$ and $\mathrm{TiO} 2$ ultra-fine particles. J.-STAGE 1993, 7, 227-233.

25. Buongiorno, J. Convective transport in nanofluids. ASME J. Heat Transf. 2006, 128, 240-250. [CrossRef]

26. Ahmad, S.; Rohni, A.M.; Pop, I. Blasius and Sakiadis problems in nanofluids. Acta Mech. 2011, 218, 195-204. [CrossRef]

27. Shafiq, A.; Lone, S.A.; Sindhu, T.N.; Al-Mdallal, Q.M.; Rasool, G. Statistical modeling for bioconvective tangent hyperbolic nanofluid towards stretching surface with zero mass flux condition. Sci. Rep. 2021, 11, 13869. [CrossRef] [PubMed]

28. Shafiq, A.; Rasool, G.; Khalique, C.M. Significance of thermal slip and convective boundary conditions in three dimensional rotating Darcy-Forchheimer nanofluid flow. Symmetry 2020, 12, 741. [CrossRef]

29. Rasool, G.; Zhang, T.; Chamkha, A.J.; Shafiq, A.; Tlili, I.; Shahzadi, G. Entropy generation and consequences of binary chemical reaction on MHD Darcy-Forchheimer Williamson nanofluid flow over non-linearly stretching surface. Entropy 2020, 22, 18. [CrossRef]

30. Abo-Dahab, S.M.; Abdelhafez, M.A.; Mebarek-Oudina, F.; Bilal, S.M. MHD Casson nanofluid flow over nonlinearly heated porous medium in presence of extending surface effect with suction/injection. Indian J. Phys. 2021, 2, 1-15.

31. Mebarek-Oudina, F.; Redouane, F.; Rajashekhar, C. Convection heat transfer of MgO-Ag/water magneto-hybrid nanoliquid flow into a special porous enclosure. Alger. J. Renew. Energy Sustain. Dev. 2020, 2, 84-95.

32. Swain, K.; Mebarek-Oudina, F.; Abo-Dahab, S.M. Influence of MWCNT/ $\mathrm{Fe}_{3} \mathrm{O}_{4}$ hybrid nanoparticles on an exponentially porous shrinking sheet with chemical reaction and slip boundary conditions. J. Therm. Anal. Calorim. 2021, 1-10. [CrossRef]

33. Sohail, M.; Shah, Z.; Tassaddiq, A.; Kumam, P.; Roy, P. Entropy generation in MHD Casson fluid flow with variable heat conductance and thermal conductivity over non-linear bi-directional stretching surface. Sci. Rep. 2020, 10, 12530. [CrossRef] [PubMed]

34. Reza, J.; Mebarek-Oudina, F.; Makinde, O.D. MHD slip flow of Cu-Kerosene nanofluid in a channel with stretching walls using 3-stage Lobatto IIIA formula. Defect Diffus. Forum 2018, 387, 51-62. [CrossRef]

35. Imran, N.; Javed, M.; Sohail, M.; Tlili, I. Simultaneous effects of heterogeneous-homogeneous reactions in peristaltic flow comprising thermal radiation: Rabinowitsch fluid model. J. Mater. Res. Technol. 2020, 9, 3520-3529. [CrossRef]

36. Rasool, G.; Shafiq, A.; Khalique, C.M.; Zhang, T. Magnetohydrodynamic Darcy-Forchheimer nanofluid flow over a nonlinear stretching sheet. Phys. Scr. 2019, 94, 105221. [CrossRef]

37. Pal, D.; Hiremath, P.S. Computational modeling of heat transfer over an unsteady stretching surface embedded in a porous medium. Meccanica 2010, 45, 415-424. [CrossRef] 